\title{
Electrical Parameters of Different Concentrations of Methyl Red in Fullerene Doped Liquid Crystal
}

\author{
M. Okutan, ${ }^{1}$ O. Köysal, ${ }^{2}$ S. E. San, ${ }^{3}$ and Y. Köysal ${ }^{4}$ \\ ${ }^{1}$ Department of Physics, Yildiz Technical University, 34210 Istanbul, Turkey \\ ${ }^{2}$ Department of Physics, Düzce University, 81620 Düzce, Turkey \\ ${ }^{3}$ Department of Physics, Gebze Institute of Technology, Kocaeli, 41400 Gebze, Turkey \\ ${ }^{4}$ Yeşilyurt Demir Çelik Vocational School, Ondokuz Mayıs University, 55330 Samsun, Turkey \\ Correspondence should be addressed to O. Köysal, oguzkoysal@gmail.com
}

Received 25 June 2012; Accepted 1 August 2012

Academic Editors: J. Bai and S. Bedanta

Copyright ( $) 2012$ M. Okutan et al. This is an open access article distributed under the Creative Commons Attribution License, which permits unrestricted use, distribution, and reproduction in any medium, provided the original work is properly cited.

Dielectric anisotropy and relaxation time of a liquid crystal (LC) system, containing fullerene and methyl red (MR) dye, were studied via impedance spectroscopy technique under a bias voltage. Dye concentration is tried to be $0.1 \%, 0.5 \%$, and $1 \%$ in host nematic liquid crystal coded E7. Dielectric permittivity and dielectric anisotropy values of the samples were investigated between the frequency ranges of 100-10 MHz. It is seen that dielectric anisotropy is strongly affected by doping ratio and this value decreases with increasing dye. Also, relaxation time $\tau$ and critical frequency $f_{c}$ values were calculated depending on voltage of different dye ratios.

\section{Introduction}

Liquid crystals (LC) are of primary importance in various device applications and their availability and compatibility with these applications are promising $[1,2]$. Also various optimization works are carried out to acquire critical information about the device thickness, threshold voltage, cell geometry, and so forth [3]. Among the tried materials, methyl red (MR-) doped samples are exceptional due to the high nonlinearity of this dye and fullerene $\mathrm{C}_{60}$ balls are also shown to be efficiently compatible with this dye because of its strong impact on the charge carriers [4]. In the scope of this work, a further optimization is aimed for tailored $\mathrm{MR}+\mathrm{C}_{60}$ doped LC systems according to the explicit effects of MR concentration on the electrical properties of the LC system. There are various works concentrating on the electro-optical characterization of LC [5]. Actually liquid crystals (LCs) are highly nonlinear materials due to their susceptible property activating under even relatively low frequency [6]. Electro-optical properties of any liquid crystal are important from the application point of view, because electro-optical properties are directly related to the structural and electronic properties [7]. Dielectric spectroscopy (DS) is the most preferred technique to understand molecular mechanisms and full electrical characterization to acquire and optimize device parameters such as relaxation time, dielectric anisotropy, and critical frequency at various bias voltage values. It this study, we have focused on the concentration effect of MR dye and fullerene doped nematic liquid crystal system. We have evaluated the dielectric character, relaxation parameter, and critical frequency as a function of frequency at various bias voltages.

\section{Experimental}

The liquid crystal used in this experiment is E7 coded nematic LC, which was obtained from Merck. E7 is the commercial LC material, which has a positive dielectric anisotropy $(\Delta \varepsilon>0)$. Actually E7 is the mixture of four nematogens (51\% K15, 25\% K21, 16\% M24, and 8\% T15). On the other hand, Methyl Red (2-(4-(dimethylamino) phenylazo) benzoic acid) is a famous dye and fullerene $\mathrm{C}_{60}$ is a highly electronegative carbon nanoparticle, which are purchased from Aldrich Chemical Company. Molecular structures of the $\mathrm{E} 7, \mathrm{MR}$, and fullerene $\mathrm{C}_{60}$ are depicted in 
TABle 1: Absorption coefficient $\alpha$, relaxation time $\tau_{\mathrm{o}}$ (with the fitting), maximum dielectric constant $\varepsilon_{\max }$, values at three different MR concentrations.

\begin{tabular}{|c|c|c|c|c|c|c|}
\hline Samples & Adj. $R$-square & $\alpha$ & Standard error & $\tau_{\mathrm{o}}(0$ Volt $)$ & Standard error & $\varepsilon_{\max }$ \\
\hline $\mathrm{E} 7 / \mathrm{C}_{60} / \mathrm{MR} 0.1 \%$ & 0.99992 & 0.00517 & $6.50 \times 10^{-4}$ & $4.8 \times 10^{-8}$ & $4.8 \times 10^{-11}$ & 3.39 \\
\hline $\mathrm{E} 7 / \mathrm{C}_{60} / \mathrm{MR} 0.5 \%$ & 0.99995 & 0.00283 & $5.12 \times 10^{-4}$ & $4.6 \times 10^{-8}$ & $3.5 \times 10^{-11}$ & 3.64 \\
\hline $\mathrm{E} 7 / \mathrm{C}_{60} / \mathrm{MR} 1.0 \%$ & 0.99974 & 0.03364 & 0.00122 & $5.3 \times 10^{-8}$ & $1.0 \times 10^{-10}$ & 3.83 \\
\hline
\end{tabular}

TABLE 2: Critical frequency $f_{c}$ and relaxation time $\tau$, values at three different MR concentrations.

\begin{tabular}{|c|c|c|c|c|c|c|}
\hline Samples & $f_{c}(0$ volt $)$ & $f_{c}(4$ volt $)$ & $f_{c}(8$ volt $)$ & $\tau(0$ volt $)$ & $\tau(4$ volt $)$ & $\tau(8$ volt $)$ \\
\hline E7/C $60 / M R 0.1 \%$ & $3.25586 \times 10^{6}$ & $3.22366 \times 10^{6}$ & 737632.40 & $4.888 \times 10^{-8}$ & $4.937 \times 10^{-8}$ & $2.157 \times 10^{-7}$ \\
\hline $\mathrm{E} 7 / \mathrm{C}_{60} / \mathrm{MR} 0.5 \%$ & $3.52359 \times 10^{6}$ & $3.44416 \times 10^{6}$ & 795446.99 & $4.516 \times 10^{-8}$ & $4.621 \times 10^{-8}$ & $2.000 \times 10^{-7}$ \\
\hline $\mathrm{E} 7 / \mathrm{C}_{60} / \mathrm{MR} 1.0 \%$ & $3.12973 \times 10^{6}$ & $3.04494 \times 10^{6}$ & 795446.99 & $5.085 \times 10^{-8}$ & $5.226 \times 10^{-8}$ & $2.000 \times 10^{-7}$ \\
\hline
\end{tabular}

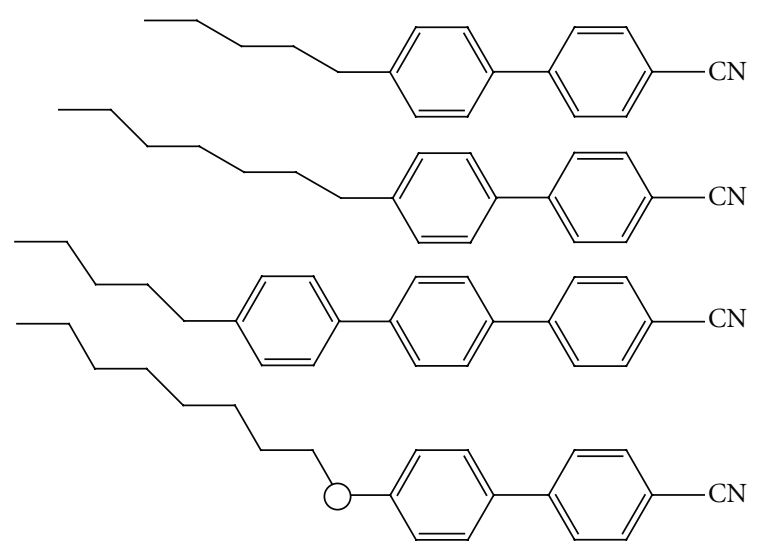

(a)

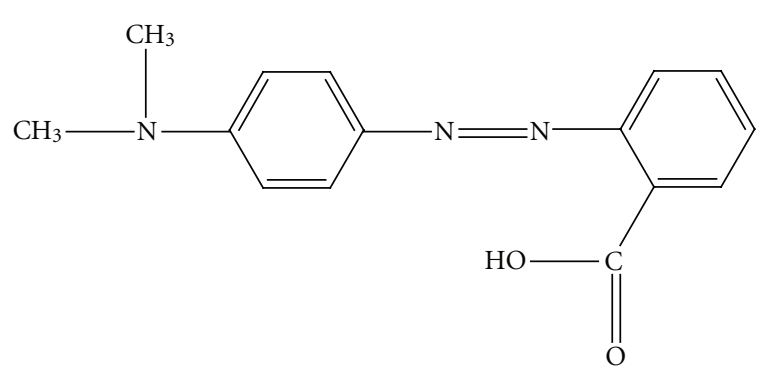

(b)

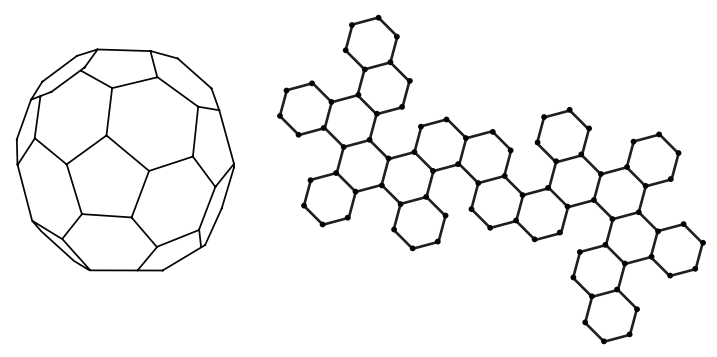

(c)

FIgURE 1: Chemical formulas of (a) nematic host, E7, (b) MR: “4dimethylaminoazobenzene-2' -carboxylic acid”, DMAABCA, and (c) fullerene, $\mathrm{C}_{60}$.

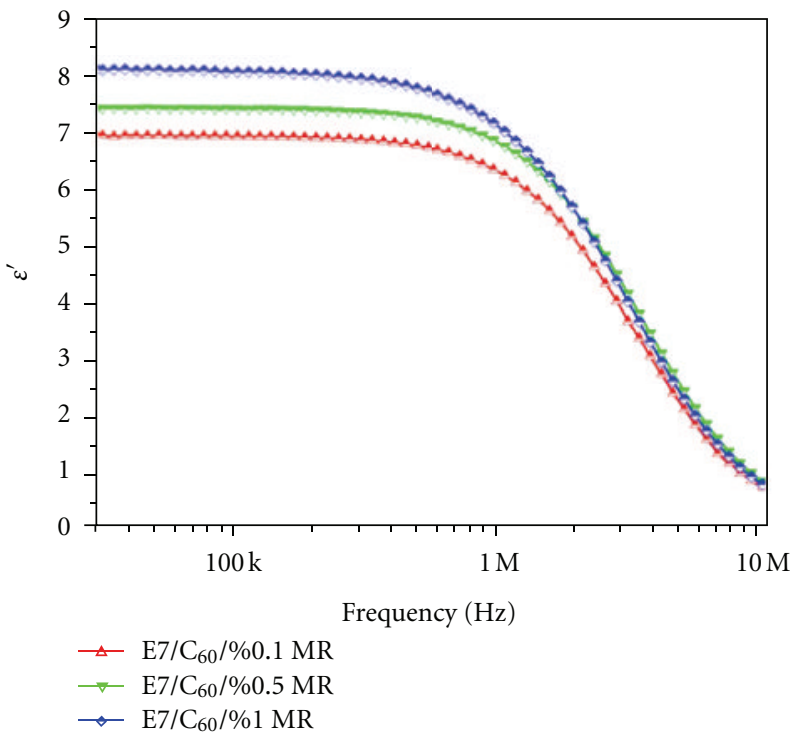

Figure 2: Dependence of real dielectric constant on frequency $\left(\varepsilon^{\prime}-\right.$ $\log f$ ) plots of the doping contents.

Figure 1. In this experimental work, ITO-(indium tin oxide)coated planarly aligned LC cells were used, whose thicknesses are $5.1 \mu \mathrm{m}$. Three samples were prepared: E7/C $60 / \mathrm{MR} 0.1 \%$ $(\mathrm{w} / \mathrm{w}), \mathrm{E} 7 / \mathrm{C}_{60} / \mathrm{MR} 0.5 \%(\mathrm{w} / \mathrm{w})$, and E7/C $60 / \mathrm{MR} 1.0 \%(\mathrm{w} / \mathrm{w})$. Samples were mixed in host LC E7 under the reinforcement of ultrasonic water-bath effect. Then doped samples of E7 were injected into cells with capillary action in isotropic phase. The measurements were performed at room temperature, where the material is in its nematic phase, by using HP 4194A Impedance Analyzer.

\section{Result and Discussion}

The complex dielectric constant of the LC is expressed as [8],

$$
\varepsilon^{*}(\omega)=\varepsilon^{\prime}(\omega)+i \varepsilon^{\prime \prime}(\omega)
$$




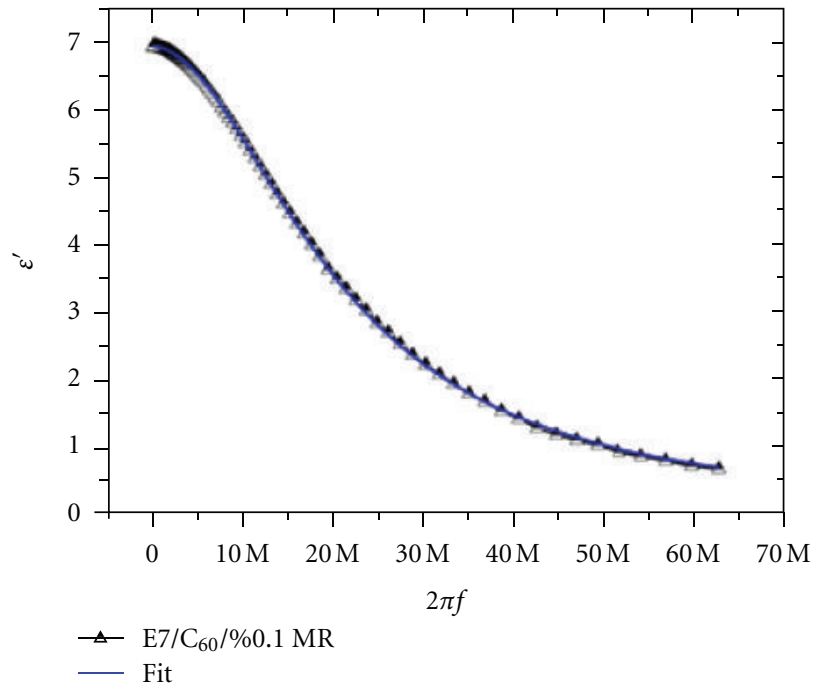

(a)

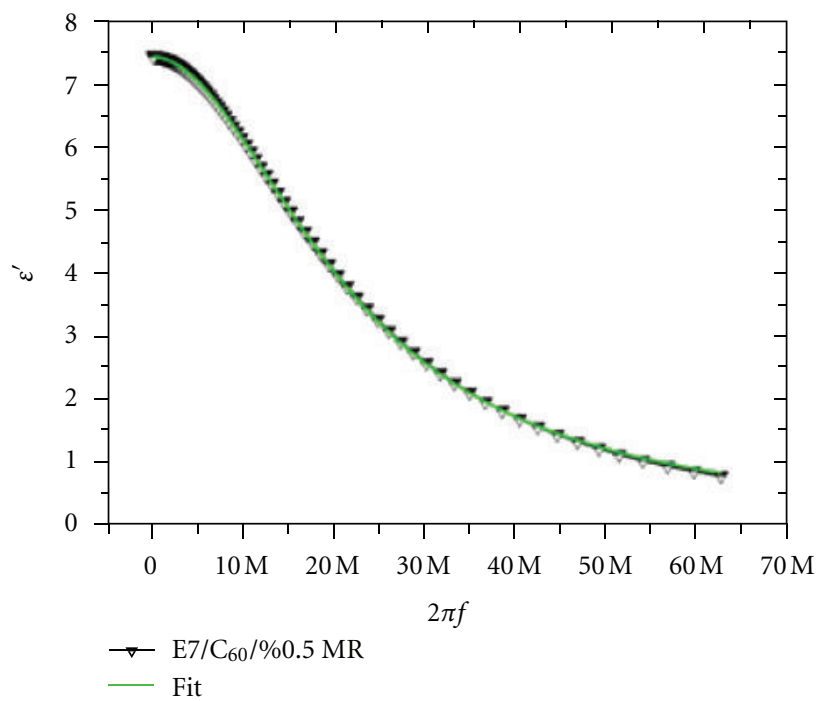

(b)

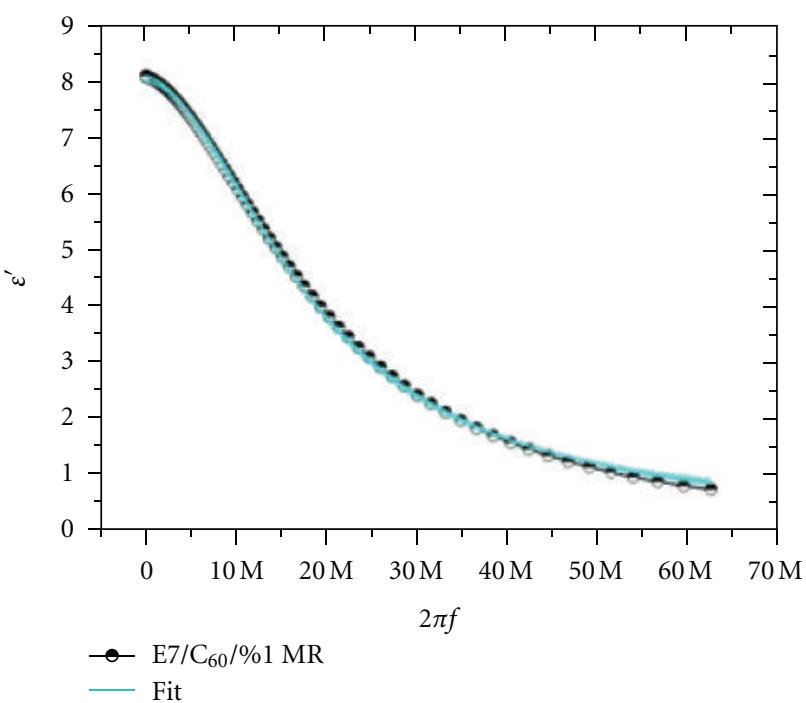

(c)

FIGURE 3: Dependence of real dielectric constant with fitting (3) on frequency $\left(\varepsilon^{\prime}-\log f\right)$ plots of the doping contents: (a) E7/ $\mathrm{C}_{60} / \% 0.1 \mathrm{MR}$, (b) $\mathrm{E} 7 / \mathrm{C}_{60} / \% 0.5 \mathrm{MR},(\mathrm{c}) \mathrm{E} 7 / \mathrm{C}_{60} / \% 1.0 \mathrm{MR}$.

where $\varepsilon^{\prime}$ is the real and $\varepsilon^{\prime \prime}$ is the imaginary parts of the dielectric constant. The first empirical expressions for $\varepsilon^{*}(\omega)$ was given by [9] and Cole-Cole equation;

$$
\varepsilon^{*}(\omega)=\varepsilon_{\infty}+\frac{\left(\varepsilon_{s}-\varepsilon_{\infty}\right)}{1+\left(i \omega \tau_{0}\right)^{1-\alpha}}
$$

$\varepsilon^{*}(w)$ is the complex relative dielectric constant, $\varepsilon_{s}$ and $\varepsilon_{\infty}$ are the static and infinite frequency dielectric constants, $\omega=$ $2 \pi$ times the frequency, and $\tau_{0}$ is a generalized relaxation time. The parameter $\alpha$ is the absorption coefficient and takes values between 0 and 1 , the real part of dielectric function is extracted from (1) as (3) for polar dielectrics and it is Debye type [10],

$$
\begin{aligned}
\mathcal{\varepsilon}^{\prime}(\omega)= & \varepsilon_{\infty}+\left(\varepsilon_{s}-\varepsilon_{\infty}\right) \\
& \times \frac{1+\left(\omega \tau_{o}\right)^{1-\alpha} \sin 1 / 2 \alpha \pi}{1+2\left(\omega \tau_{o}\right)^{1-\alpha} \sin 1 / 2 \alpha \pi+\left(\omega \tau_{o}\right)^{2(1-\alpha)}} .
\end{aligned}
$$

We have calculated $\tau_{0}$ from (3) and it is fitted by the results given in Figure 2. Figure 3 shows this precise fit, which is arranged with respect to the angular frequency. The calculated $\tau_{0}$ and $\alpha$ value are given in Table 1. In fact, $\alpha$ and $\tau_{0}$ values are firstly decreasing with the MR doping from $0.1 \%$ till $0.5 \%(\mathrm{w} / \mathrm{w})$ and then these values start to increase 


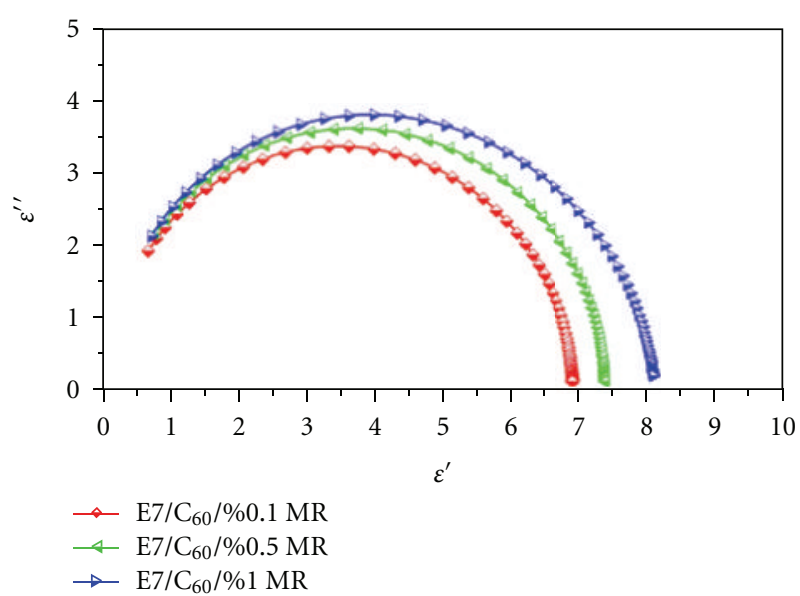

FIgURE 4: Cole-Cole plots of the doping contents.

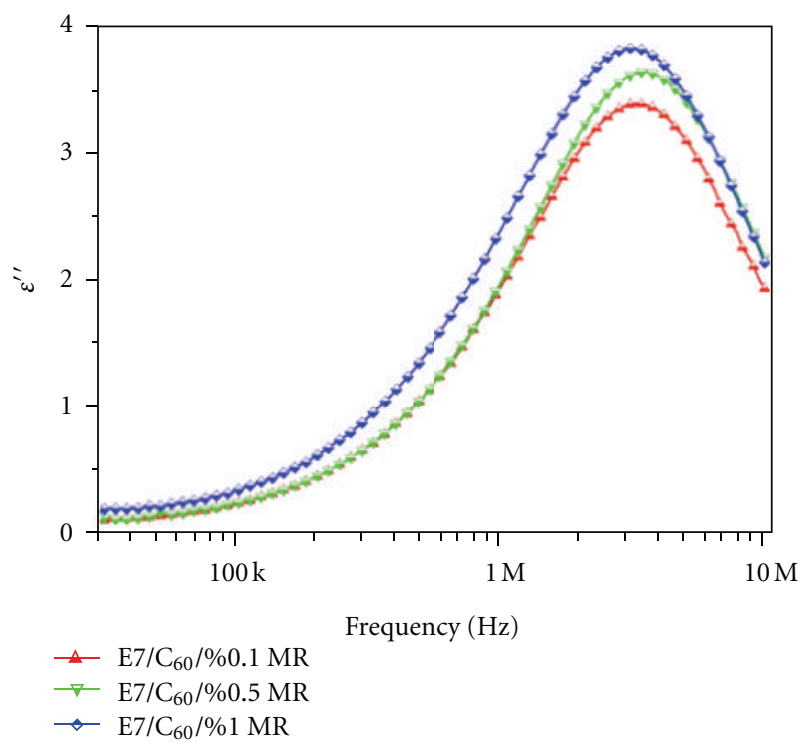

FIGURE 5: Dependence of imaginary dielectric constant on frequency $\left(\varepsilon^{\prime \prime}-\log f\right)$ plots of the doping contents.

after $0.5 \%$ doping amount and this situation is actually in accordance with the optimization of dye concentration at $0.5 \%$. The decrease in the relaxation times value of ColeCole equation is caused by doping dependency of molecular dynamism. In addition the radius of Cole-Cole plot is increased with the dye doping. This accordance is depicted in Figure 4. Briefly speaking $\tau_{0}$ and $\alpha$ value depend on dye percentage in such a way that $0.5 \%$ makes minimum for these values and $\varepsilon_{\max }$ values are continuously increasing with doping. This is because, the dye causes larger amount of loss of energies due to the molecular density increase of the LC system,

$$
\varepsilon^{\prime \prime}(\omega)=\left(\varepsilon_{s}-\varepsilon_{\infty}\right) \frac{\left(\omega \tau_{0}\right)^{1-\alpha} \cos 1 / 2 \alpha \pi}{1+2\left(\omega \tau_{0}\right)^{1-\alpha} \sin 1 / 2 \alpha \pi+\left(\omega \tau_{0}\right)^{2(1-\alpha)}} .
$$

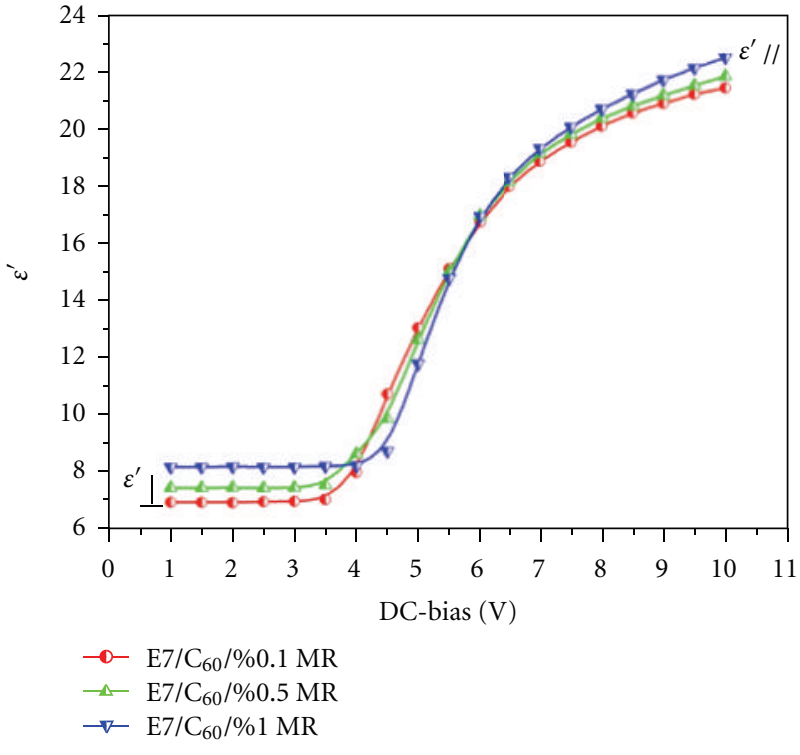

Figure 6: Dependence of real dielectric constant on direct current bias voltage at spot frequency $10 \mathrm{kHz}\left(\varepsilon^{\prime}-\mathrm{V}\right)$ plots of the doping contents.

TAble 3: Dielectric Anisotropy, $\Delta \varepsilon$, values of the samples.

\begin{tabular}{lc}
\hline Samples & $\Delta \varepsilon(10 \mathrm{k} \mathrm{Hz})$ \\
\hline E7/C $_{60} / \mathrm{MR} 0.1 \%$ & 14.545 \\
$\mathrm{E} 7 / \mathrm{C}_{60} / \mathrm{MR} 0.5 \%$ & 14.448 \\
$\mathrm{E}^{2} / \mathrm{C}_{60} / \mathrm{MR} 1.0 \%$ & 14.375 \\
\hline
\end{tabular}

The imaginary part of the dielectric constant is shown in Figure 5. The critical frequency $f_{c}$ and relaxation time $\tau$ are determined from this graph and given in Table 2. If we read this table, we see that critical frequency is decreased with the doping in consistency with what happened in $\tau_{0}$ and $\alpha$. Also maximum point intensity of the peaks in Figure 5 is firstly shifted forward and then backward according to concentration. One can calculate the relaxation time from these peaks directly with the help of $\tau=1 /\left(2 \pi f_{c}\right)$ if we compare the relaxation time values with the previously obtained relaxation times acquired from Debye equation (3). In other words, if we compare $\tau_{0}$ of Table 1 and $\tau$ of Table 2 , we observe a good consistency indeed.

The dielectric permittivity of the nematic liquid crystals is anisotropic due to long-range orientation order. Dielectric behavior of a nematic liquid crystal is described by two dielectric constants, $\varepsilon_{\| \mid}$and $\varepsilon_{\perp}$ and the dielectric anisotropy is defined as $\Delta \varepsilon=\varepsilon_{\|}-\varepsilon_{\perp}$ [11]. Dielectric anisotropy $(\Delta \varepsilon)$ is one of the most important physical properties of liquid crystalline compounds, which in essence determines the lower threshold voltages of liquid crystal displays (LCDs) [12]. Real part of dielectric constant versus voltage was shown in Figure 6 and dielectric anisotropy $\Delta \varepsilon$ values were calculated at $10 \mathrm{kHz}$ spot frequency. These $\Delta \varepsilon$ values are presented in Table 3. Variation of $\Delta \varepsilon$ with respect to 
concentration can be attributed to impurity in such a way that as the impurity increases $\Delta \varepsilon$ decreases.

\section{Conclusions}

Concentration dependency of molecular orientation in dyedoped nematic LC was examined through a substantial sample LC system, which contains a famous dye MR as a doping agent. Optimization of dye concentration is monitored via different approaches of electrical characterizations and investigations. The accordance of these mentioned investigations are verified by comparing their outcomes. Actually, Debye type is an ideal situation for proposing efficient dye doped LCs. Ideal compatibility of the LC system to Debye type is realized in case of $\alpha=0$. The lowest $\alpha$ is attained with $0.5 \%$ MR doping in LC host in our design.

\section{References}

[1] S. E. San, O. Köysal, and M. Okutan, "Laser-induced dielectric anisotropy of a hybrid liquid crystal composite made up of methyl red and fullerene C60," Journal of Non-Crystalline Solids, vol. 351, no. 33-36, pp. 2798-2801, 2005.

[2] M. Okutan, O. Köysal, and S. E. San, "Effect of laser illumination on the electro optical characters of dye doped nematic liquid crystals," Displays, vol. 24, no. 2, pp. 81-84, 2003.

[3] M. Okutan, F. Yakuphanoglu, S. E. San, and O. Koysal, "Impedance spectroscopy and dielectric anisotropy-type analysis in dye-doped nematic liquid crystals having different preliminary orientations," Physica B, vol. 368, no. 1-4, pp. 308317, 2005.

[4] E. Şentürk, M. Okutan, S. E. San, and O. Köysal, "Debye type dielectric relaxation in carbon nano-balls" and 4-DMAABCA acid doped E7 coded nematic liquid crystal," Journal of NonCrystalline Solids, vol. 354, no. 30, pp. 3525-3528, 2008.

[5] O. Köysal, M. Okutan, M. Durmuş, F. Yakuphanoglu, S. E. San, and V. Ahsen, "Diffraction efficiency and dielectric relaxation properties of nickel phthalocyanine doped nematic liquid crystal," Synthetic Metals, vol. 156, no. 1, pp. 58-64, 2006.

[6] S. E. San, M. Okutan, O. Köysal, H. Ono, and N. Kawatsuki, "Dielectric properties of a side-chain liquid crystalline polymer under laser induced circumstances," Optics Communications, vol. 238, no. 1-3, pp. 79-84, 2004.

[7] F. Yakuphanoglu, M. Durmuş, M. Okutan, O. Köysal, and V. Ahsen, "The refractive index dispersion and the optical constants of liquid crystal metal-free and nickel(II) phthalocyanines," Physica B, vol. 373, no. 2, pp. 262-266, 2006.

[8] S. Matsumoto and I. Kadota, Liquid Crystals-Fundamentals and Applications, Kogyochosakai, Tokyo, Japan, 1991.

[9] K. S. Cole and R. H. Cole, "Dispersion and absorption in dielectrics I. Alternating current characteristics," The Journal of Chemical Physics, vol. 9, no. 4, pp. 341-351, 1941.

[10] G. G. Raju, Dielectrics in Electric Fields, Marcel Dekker, New York, NY, USA, 2003.

[11] E. Lueder, Liquid Crystal Displays, John Wiley \& Sons, 2001.

[12] T. Scheffer and J. Nehring, Applications and Uses in Liquid Crystals, vol. 1, World Scientific, Singapore, 1990. 

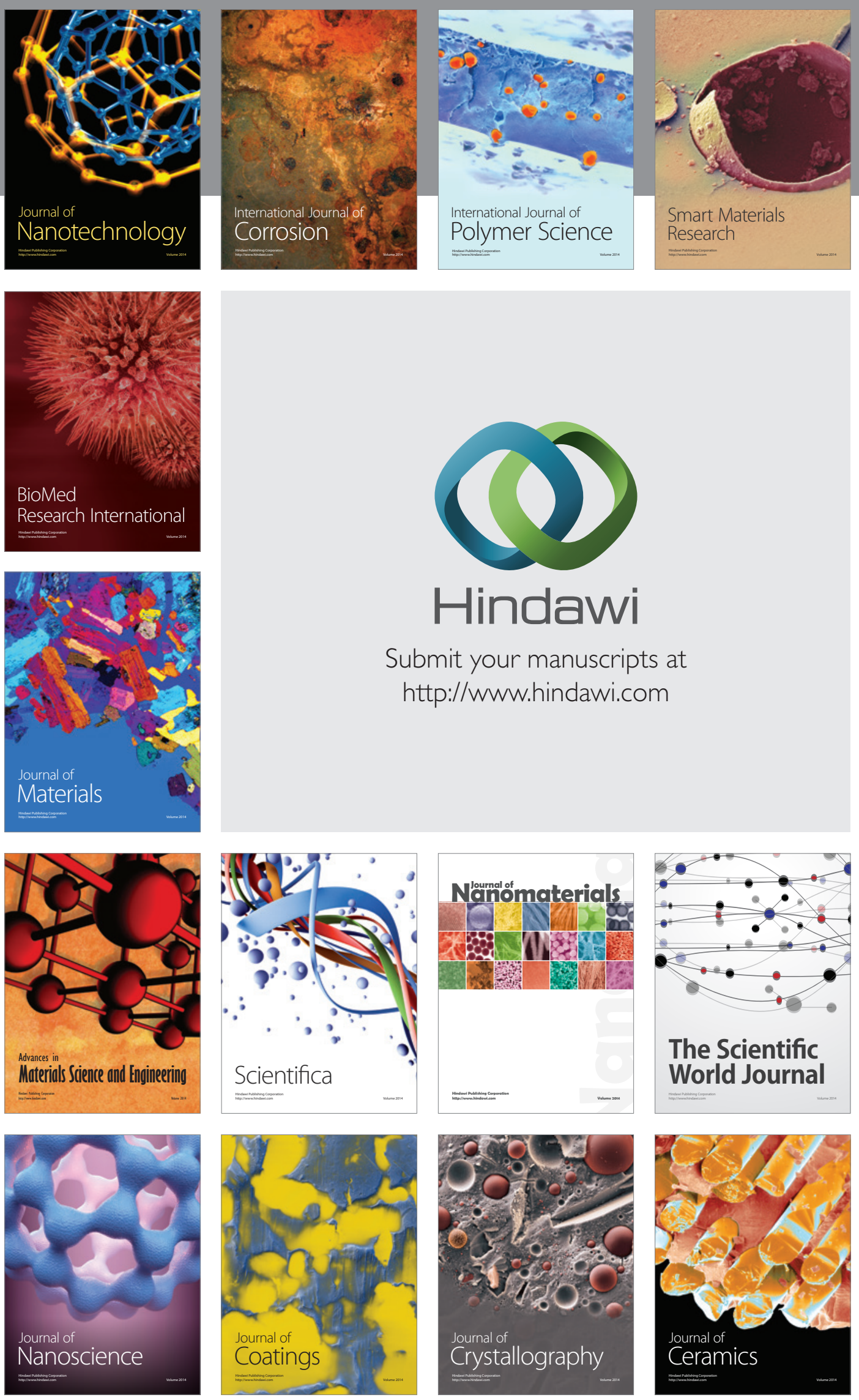

The Scientific World Journal

Submit your manuscripts at

http://www.hindawi.com

\section{World Journal}

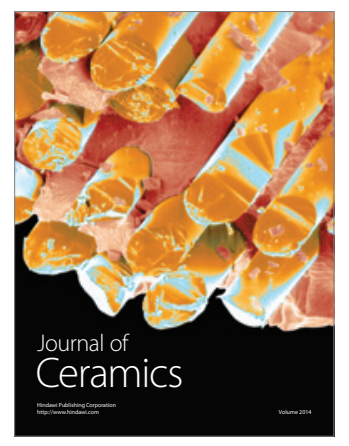

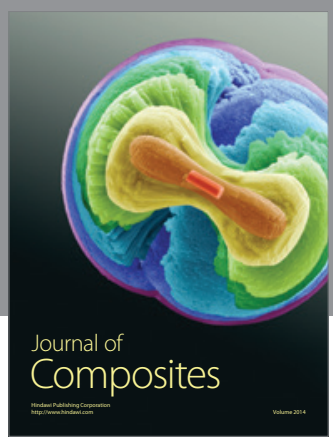
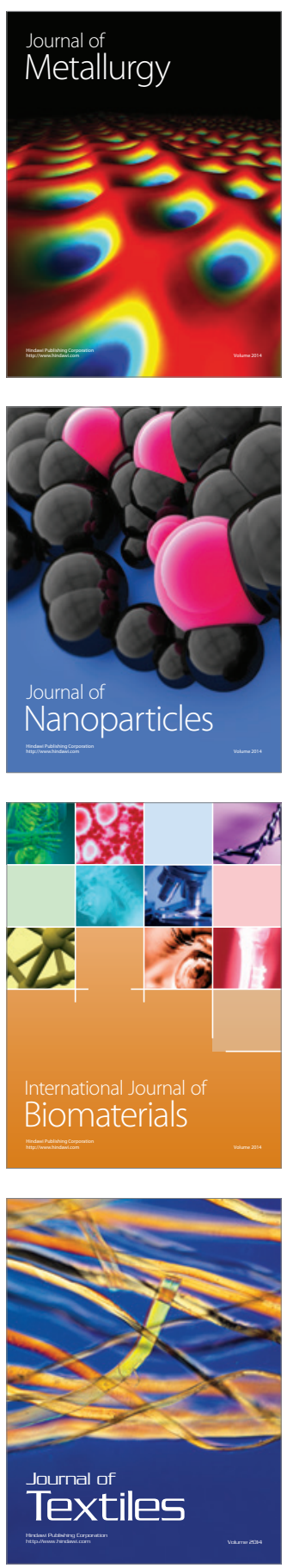